\title{
Predicting potential ranges of primary malaria vectors and malaria in northern South America based on projected changes in climate, land cover and human population
}

Temitope O. Alimi ${ }^{1 *}$, Douglas O. Fuller ${ }^{2}$, Whitney A. Qualls ${ }^{3}$, Socrates V. Herrera ${ }^{4,5}$, Myriam Arevalo-Herrera ${ }^{4,5}$, Martha L. Quinones ${ }^{6}$, Marcus V. G. Lacerda ${ }^{7,8}$ and John C. Beier ${ }^{3}$

\begin{abstract}
Background: Changes in land use and land cover (LULC) as well as climate are likely to affect the geographic distribution of malaria vectors and parasites in the coming decades. At present, malaria transmission is concentrated mainly in the Amazon basin where extensive agriculture, mining, and logging activities have resulted in changes to local and regional hydrology, massive loss of forest cover, and increased contact between malaria vectors and hosts.

Methods: Employing presence-only records, bioclimatic, topographic, hydrologic, LULC and human population data, we modeled the distribution of malaria and two of its dominant vectors, Anopheles darlingi, and Anopheles nuneztovari s.l. in northern South America using the species distribution modeling platform Maxent.

Results: Results from our land change modeling indicate that about $70,000 \mathrm{~km}^{2}$ of forest land would be lost by 2050 and $78,000 \mathrm{~km}^{2}$ by 2070 compared to 2010. The Maxent model predicted zones of relatively high habitat suitability for malaria and the vectors mainly within the Amazon and along coastlines. While areas with malaria are expected to decrease in line with current downward trends, both vectors are predicted to experience range expansions in the future. Elevation, annual precipitation and temperature were influential in all models both current and future. Human population mostly affected An. darlingi distribution while LULC changes influenced An. nuneztovari s.l. distribution.
\end{abstract}

Conclusion: As the region tackles the challenge of malaria elimination, investigations such as this could be useful for planning and management purposes and aid in predicting and addressing potential impediments to elimination.

Keywords: Species distribution models, Maxent, Malaria, An. darlingi, An. nuneztovari s.l, Land-use changes, Climate change, Population expansion, South America

\footnotetext{
* Correspondence: t.alimi@umiami.edu

${ }^{1}$ Abess Center for Ecosystem Science and Policy, University of Miami, Coral

Gables, Florida, USA

Full list of author information is available at the end of the article
} 


\section{Background}

As more countries in Latin America experience economic growth brought about by increased external trade and natural resource exploitation [1], the continuous demand for land to accommodate growing infrastructural development, agricultural and livestock production and frontier settlements, especially in the Amazon, is leading to rapid deforestation [2, 3]. Additional factors such as accelerated rate of internal migrations, expected global climate changes and population expansion [4] may influence the transmission of malaria and other vector-borne diseases $[3,5]$. However, the direction of this influence is uncertain; vulnerability to malaria may increase if deforestation continues unabated, or the region could reach a tipping point and experience a major climate shift that may not favor vectors. This could occur as feedbacks between land cover and climate change in the Amazon may lead to rapid (decadal scale) changes within the climate of the Amazon basin itself. For example, recent studies point to the increasing effects of drought in the Amazon on species diversity, biomass, and fires, which appear to be linked to deforestation over the past 30 years [6].

Malaria has persistently plagued Latin America [7], and while there has been marked progress in malaria control in the past decade [8], environmental and population changes potentially threaten these gains by creating conducive habitats $[9,10]$ and increased availability of blood meals [4] for malaria vectors. Moreover, future temperature changes and ecosystem alterations from local land use patterns may impact malaria transmission by accelerating life cycles of parasites and mosquitoes $[11,12]$. At present, our knowledge of both malaria and vector distribution in the region is incomplete [7] although there have been a number of efforts to model the distributions [13-22]. Filling this knowledge gap would help to mitigate potential obstacles to malaria elimination by lending new insights into how vectors and the disease are likely to shift given a business-as-usual scenario.

Malaria risk and the distribution of dominant vectors in Latin America are heterogeneous. Approximately 120 million people in Latin America are at risk of malaria transmission, with an estimated 25 million of them at high risk [8]. Three-quarters of infections are caused by Plasmodium vivax (Grassi and Feletti 1890), while P. falciparum (Welch 1897) is responsible for the remaining $25 \%$ $[8,23]$. The burden of malaria in the region is however borne by countries in the Amazon rainforest in northern South America (NSA) where $90 \%$ of cases are reported [24]. Transmission occurs through infected bites from Anopheles darlingi (Root 1926) and An. nuneztovari s.l. (Gabaldon 1940), two of the dominant vectors in this region [13]. Anopheles darlingi is one of the most efficient and anthropophilic malaria vectors [14], and has been implicated as the primary vector for $P$. falciparum and $P$. vivax in the endemic areas of the region $[15,25]$. Anopheles nuneztovari s.l. is a species complex in South America comprising of at least two species: An. nuneztovari A (from Suriname and Brazil), and An. nuneztovari B/C (from Colombia and Venezuela) [26, 27]. Anopheles nuneztovari $\mathrm{B} / \mathrm{C}$ is considered a dominant vector because it bites late into the evening and throughout the night [26], whereas the status of An. nuneztovari A as a vector in the Brazilian Amazon is still unresolved [28]. Evidence suggests that both $A n$. darlingi and An. nuneztovari s.l. are found in altered environments [29-32] and An. darlingi prefers locations close to human settlements in frontier agricultural areas in parts of the Amazon [5]. Based on these characteristics and expected bioclimatic changes, an understanding of the distribution of malaria and its vectors, both now and in the future, is needed to aid our preparedness for effective operational malaria control.

A number of attempts have been made to map malaria and vector distribution in the Americas. Gething et al. generated global maps of $P$. falciparum [16] and $P$. vivax [17] endemicity in 2010 using georeferenced parasite rates and incidence data, climatic variables (temperature and aridity) and human population data. Their results showed all nine countries in NSA as having stable or unstable malaria risk $[16,17]$ and though the Americas accounted for $22 \%$ of global land area at risk, they estimated that the region has $6 \%$ of the global at-risk population for $P$. vivax infection [17].

Previous efforts to map mosquito distributions in the Americas have involved multiple genera [18], or species $[13-15,19,20]$ or have been based on single species [22] and at different geographic scales, ranging from continental or sub-continental $[13,14,18,22]$ to national $[19,21]$. Foley and colleagues [18] used geo-located museum specimen records to model mosquito species richness and endemicity in the Neotropics. By employing climatic and LULC information, Sinka et al. [13] mapped the distributions of dominant Anopheles in the region whereas an eco-regional approach for the Neotropics was used by Rubio-Palis and Zimmerman [20]. Fuller et al. [22] modeled the distribution of An. albimanus (Wiedemann 1820) in the Mesoamerican and Caribbean basin based on climatic and topographic data. While some previous attempts have been criticized as lacking a sufficient number of occurrence records and simplicity of techniques used [13], more recent attempts have employed techniques modeling the realized niche or habitat suitability of species. Such studies have generally limited their evaluations of mosquito distribution to bioclimatic, topographic variables [13, 22], and LULC [13]. Moreover, with the exception of Fuller et al. [22], who modeled future distribution of $A n$. albimanus by 2080, most studies that have focused on Neotropical vectors have limited their investigations to current distribution patterns. However, the increasing availability of 
downscaled climate projections from General Circulation Models (GCMs) creates new opportunities to drive modeling techniques that can project future distributions as a function of climate as well as land cover.

Numerous approaches to model species distribution are available, including the presence-only maximum entropy method implemented through the modeling platform, Maxent [33, 34]. Although originally designed to model species habitat suitability, the maximum entropy approach to probabilistic modeling has applications well beyond species niche modeling. For example, some studies have used Maxent to project disease distributions such as dengue [35] and Chagas disease [36]. Thus, using models of this type, one may be able to visualize the current distribution of malaria and where it is likely to persist in the future or shift, and prioritize such areas for current eliminations efforts. In addition, by overlaying current and future distributions, one can visualize where malaria may be continuously problematic through time as a function of climate and land cover change. In this study we model the distribution of malaria, An. darlingi, and An. nuneztovari s.l. in NSA using bioclimatic, topographic, hydrologic, as well as LULC and population data using Maxent. The aims are to: (i) show the current spatial distribution and examine how the above factors may influence species habitat suitability in NSA and (ii) investigate the potential influence of changes in climate, LULC and population on future species range.

\section{Methods}

Our study area comprises parts of Bolivia, Brazil, Colombia, Ecuador, French Guiana, Guyana, Peru, Suriname and Venezuela (Fig. 1), and includes all parts of the Amazon rainforest. This area has the combination of socioenvironmental and climatic conditions that favor the proliferation of vectors species and malaria.

\section{Vectors and disease occurrence data}

We obtained georeferenced point collection data with records of locations where both larvae and adult $A n$. darlingi and An. nuneztovari s.l. were sampled (Fig. 1) through VectorMap [37] and the Global Biodiversity Information Facility [38]. These records were collected by different investigators between 1980 and 2007 and made available through an online spatial database, the MosquitoMap [39]. We checked the downloaded data points, excluding those with high estimated spatial uncertainty and multiple entries. Additional sample locations of both species were gathered through field studies conducted in Colombia [40].

Anopheles darlingi is present in a wide range in our study area: from the Amazonian south of Venezuela [41, 42], the sparsely populated interiors of Guyana, Suriname and French Guiana [41], to Brazil [15], Amazonian plains of
Ecuador [14] and parts of Colombia [43]. It is a lowland, riverine, forest dwelling species whose larvae are often found in lagoons, lakes, slow flowing streams, rivers with shaded clear water, often associated with aquatic macrophytes (AMs) along the shallow margins of water bodies $[13,29,30,44]$. Larval samples from uncharacteristic locations such as slightly brackish water [29], turbid, polluted water [31], abandoned gold mine dugouts [32] or areas with limited forest cover [5] have also been reported, indicating the influence of environmental changes on its spread. The species is mostly exophilic $[25,32]$ but exhibits both endophagic [41] and exophagic biting behaviors [45].

Anopheles nuneztovari s.l. is found extensively in our study area [46], serving as a primary vector in western Venezuela and north-western Colombia [46], and a probable vector in Suriname [44]. Its larvae are found in both sunlit and shaded habitats in temporary or permanent waterbodies which may contain fresh, clear, still or flowing water with AMs [29, 43]. Samples have also been collected in disturbed habitats such as brick pits and turbid water bodies $[29,31]$ where this species is readily able to colonize and dominate in disturbed environments [47]. Anopheles nuneztovari s.l. is both anthropophilic and zoophilic, rests outdoors [48], and is both exophagic [25, 43, 47-49] and endophilic [48].

Malaria in our study area, caused by both $P$. vivax and $P$. falciparum, is mostly found in Brazil, Colombia, and Venezuela, where $72 \%$ of cases in 2013 occurred [8]. The Brazilian Amazon is the core area where the most malaria infections occur in the region [50]. We therefore obtained malaria incidence data comprising of both parasite species ( $75 \%$ of all infections are caused by $P$. vivax) for Amazonas state in Brazil through SIVEPMalaria (http://200.214.130.44/sivep_malaria/), the national official malaria database. The incidence data originated from passive case detection of patients who reported symptoms consistent with malaria and were cases confirmed using thick-blood smears as is currently the standard procedure in clinics in Brazil. However, we were unable to account for the treatment seeking rates in the area as a review of literature suggests that these are not well established for the Amazon as a whole.

These incidence data were originally aggregated by municipality and then converted to point data using a point-in-polygon analysis in ArcGIS $^{\circ}$ [51] before being used in the disease distribution modeling (Fig. 1). A population weighting was applied to determine the location of each point representing a municipality, to ensure that the distribution of points were influenced by population clusters rather than being randomly situated in the center of the polygon. Bearing in mind that malaria is usually a rural disease, away from the most densely populated areas, the weighting was carried out such that the points were situated in the least densely populated 

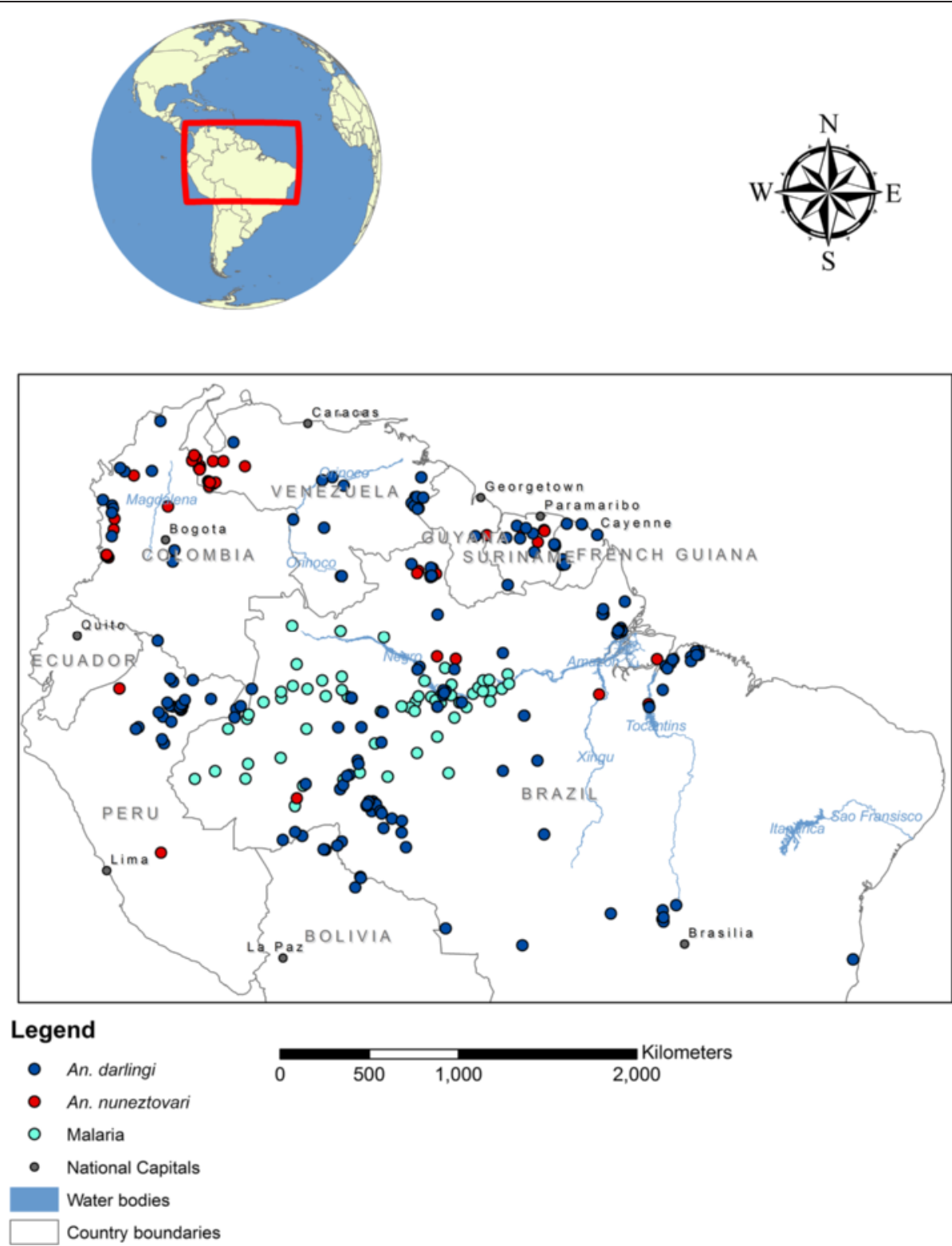

Fig. 1 An. darlingi, An. nuneztovari s.l. and malaria sample locations. Malaria cases by municipality in Amazonas state of Brazil were converted to population-weighted points representing each municipality

areas. This was achieved by first creating a fuzzy layer from the population density raster on the premise that populations between 2 and 150 per square kilometer are sufficient for malaria transmission. This fuzzy layer was then converted to points and a spatial join between the points and the municipality polygons was subsequently implemented. The location of the mean center of points was weighted by low population and interpolated from the surrounding points within each municipality. Such weighting was particularly necessary to mitigate limitations of the data. For instance, the aggregation of cases by municipality gave no indication about the exact location of transmission or clustering of cases; however, by locating the points based on population density, a point distribution was achieved.

\section{Environmental variables}

We employed 23 environmental variables as possible explanatory factors in our distribution models. Nineteen bioclimatic variables representing various measures of temperature and precipitation were obtained from WorldClim [52]. This is a set of interpolated global climate surfaces at $\sim 1 \mathrm{~km}$ spatial resolution [53]. The layers representing current conditions (1950-2000) and future projections for 2050 and 2070 were collated. The future climate projection layers were chosen from two 
models from the Intergovernmental Panel on Climate Change (IPCC) Fifth Assessment Report of 2014 [54] - the National Aeronautics and Space Agency (NASA) Goddard Institute for Space Studies (GISS-E2-R) models, and the Hadley Center (HadGEM2-AO) models. The models were chosen because their representation of future predictions of precipitation and temperature in the study area were varied, potentially leading to a range of prediction scenarios. The NASA model generally predicted warmer temperatures compared to the Hadley model in the study area by 2050 and 2070. For precipitation, the Hadley model predicted much drier conditions around the Andes for both periods compared to the NASA models (see Additional file 1), and wetter conditions in parts of the Amazon, and the Atlantic coasts from southern Venezuela to southern Brazil. The NASA model on the other hand predicted higher precipitation in many patches in the Amazon. The climate surfaces were generated under four different greenhouse gas concentration trajectories called representative concentration pathways (RCP). For our analyses, we utilized the most conservative climate projections under the first, RCP 2.6, which assumes a peak in global annual greenhouse gas emissions between 2010-2020, after which emissions are expected to decline [55]. The scenario depicts mean global temperature increase of $1{ }^{\circ} \mathrm{C}$ (range from 0.4 to 1.6 ) by mid- $21^{\text {st }}$ century (i.e., 2046-2065) [56].

To account for the altitudinal gradients in the area, which is an important consideration for mosquito and malaria dispersal, we obtained data on elevation from the Shuttle Radar Topographic Mission (SRTM) [57]. An additional factor, the topographic wetness index (TWI) was derived from this topographic information as a measure of soil moisture content especially in low elevation areas [58], providing an indication of potential vector breeding sites. These two layers were gridded to $1 \mathrm{~km}$ resolution to retain environmental heterogeneity and ensure data compatibility with other variables. The availability and distribution of human hosts as potential sources of blood meals for vectors was represented using population density layer for 2010 provided by the LandScan product [59]. Since environmental changes, whether natural or human-induced, play an important role in vector and malaria distribution [60], we included changing land use land cover (LULC) patterns in our analysis. The LULC data was derived from Moderate Resolution Imaging Spectrometer (MODIS) imagery for 2001 and 2010 [61], containing 17 LULC classes generated using the International Geosphere-Biosphere Programme (IGBP) classification scheme. The IGBP classes were aggregated into two land cover classes for our land cover projection modeling: forest (containing all forest classes) and non-forested (containing all other classes excluding water bodies).

\section{Predicting LULC and population changes}

To adequately predict distributions of the vectors and malaria for 2050 and 2070, future LULC scenarios as well as population changes in our study area for the requisite periods were projected in Idrisi Selva [62]. The land change modeler (LCM) was used to estimate LULC changes. LCM is an application designed to model land conversion by using historical changes from land cover maps to project future land use change scenarios [63]. The process began with the introduction of land cover maps of the two time periods, 2001 and 2010 to assess changes between them. By incorporating change drivers related to forest access such as distance from roads, water bodies [64], past deforestation [61], and elevation [57], land use transition potentials were produced. Probability of change (transition probabilities) between both time periods was quantified using the Markov transition matrix [65]. We assumed the transition probabilities remain unchanged over time, and used these to project future LULC scenarios for 2050 and 2070. LULC change was estimated using the Area module in Idrisi and each land cover map for 2010, 2050 and 2070 entered as a categorical variable in Maxent for the species distribution modeling for the respective time periods.

Population changes for 2050 and 2070 were predicted by applying an exponential population function (Equation 1) to the base population year, 2010. Using an average annual growth rate of $1.1 \%$ across the region [66], the projected population for the two time periods was estimated by the formula:

$$
\mathrm{P}=\mathrm{P}_{0} \cdot \mathrm{e}^{\mathrm{rt}}
$$

Where $\mathrm{P}=$ Estimated population, $\mathrm{P}_{0}=$ Initial population, $r=$ rate of natural increase, and $t=$ number of years between $\mathrm{P}$ and $\mathrm{P}_{0}$.

\section{Modeling species and malaria distributions using maximum entropy}

Maxent is a machine-learning method that estimates the distribution of a target by finding the distribution with the largest spread [67]. Maxent predicts species habitat suitability by incorporating its documented occurrence points with relevant environmental predictors in a defined geographic space $[68,69]$, subject to the constraint that the expected value of each predictor under this estimated distribution matches its empirical average [70]. The output is the relative habitat suitability calculated by converting the exponential values of the raw estimates of suitability to logistic values [70].

All cleaned presence data for An. darlingi $(n=271)$, An. nuneztovari s.l. $(n=175)$ and Malaria $(n=62)$ (Fig. 1$)$ were used in the distribution models. Twenty-five percent of each of the datasets were randomly selected to 
independently assess the accuracy of each model while the rest were used for model training. The collection data used were suited for our analyses at $\sim 1 \mathrm{~km}$ resolution because the distance between the data points were relatively greater than $1 \mathrm{~km}$. The resolution was selected to be consistent with the highest resolution available for the environmental layers as has been used by other studies e.g., Drake and Beier, 2014 [71].

Due to a lack of absence data, a set of pseudo-absence (background) points were created for each species as Maxent determines habitat suitability by relating the values of predictors at presence points with those of randomly generated pseudo-absence points within the same area $[72,73]$. Knowing that the number of pseudoabsences affects the models [13], we created multiple background points in ratios 1:1, 2:1, 5:1, and 10:1 to presence points for the vectors and evaluated the model results both visually (mapped distribution) and statistically (how well the area under the curve (AUC) improved). Based on the evaluation, the optimal ratio of background to presence points was 1:1 for the vectors while the default 10, 000 background points in Maxent was optimal for malaria. To account for the inherent sampling bias in the presence data [69], bias files encompassing the area of study were created for each species to ensure that both the occurrence and pseudo-absence points had the same geographical bias [74]. We tested for multi-collinearity among pairs of predictors and excluded one predictor in each pair that showed high correlation (Table 1) in the vector models. However all 23 predictors were used in the malaria model as AUC value improved when this was done.

Modeling was carried out by identifying the current niche suitability drivers from the current models and based on the assumption that all factors remained constant except a changing landscape, we applied these to the future scenarios. We used auto features for model generation, an option which allowed the set of features used to be determined by the number of presence points, using general empirically-derived rules. All modeling was performed using the subsample replicated run in Maxent $\mathrm{v}$ 3.3.3 $\mathrm{k}$, the most current version of the software [75].

\section{Assessing model performance}

Various measures of model performance were used in our accuracy assessment. The model's ability to discriminate between species presence and absence sites was measured using AUC [76]. Generally, models with $\mathrm{AUC} \leq 0.5$ are deemed to behave no better than random, while an AUC of 1 indicates a perfect fit between observed and predicted surfaces [77]. In practice, models with AUC above 0.75 are considered useful and results applicable [70]. Further assessment of model performance requires setting a threshold at which species habitat suitability can be converted to binary predictions of species presence or absence $[78,79]$. While many threshold approaches are available, we chose the sensitivity-specificity equality approach that has been identified as one of the best performing thresholds [78]. The equal sensitivity- specificity threshold (ETSS) maximizes the absolute value of the difference

Table 1 MaxEnt models validation parameters evaluated using test points

\begin{tabular}{|c|c|c|c|c|c|c|c|c|}
\hline Species & Time/Model & Parameters in model & Training AUC & Test AUC & Mean $\{\mathrm{sd}\}^{b}$ & ETSS & Omission rate & TSS \\
\hline \multirow[t]{5}{*}{ Malaria } & Current & 23 & 0.93 & 0.9 & $0.53\{0.23\}$ & 0.271 & $0.25^{*}$ & 0.57 \\
\hline & 2050 (Hadley) & & & & $0.49\{0.16\}$ & & & \\
\hline & 2050 (NASA) & & & & $0.46\{0.18\}$ & & & \\
\hline & 2070 (Hadley) & & & & $0.46\{0.17\}$ & & & \\
\hline & 2070 (NASA) & & & & $0.45\{0.19\}$ & & & \\
\hline \multirow[t]{5}{*}{ An. darlingi ${ }^{a}$} & Current & 13 & 0.77 & 0.75 & $0.51\{0.12\}$ & 0.463 & $0.34^{*}$ & 0.58 \\
\hline & 2050 (Hadley) & & & & $0.51\{0.14\}$ & & & \\
\hline & 2050 (NASA) & & & & $0.50\{0.13\}$ & & & \\
\hline & 2070 (Hadley) & & & & $0.51\{0.13\}$ & & & \\
\hline & 2070 (NASA) & & & & $0.51\{0.13\}$ & & & \\
\hline \multirow[t]{5}{*}{ An. nuneztovari s.l. ${ }^{a}$} & Current & & 0.8 & 0.79 & $0.53\{0.14\}$ & 0.492 & $0.3^{*}$ & 0.68 \\
\hline & 2050 (Hadley) & & & & $0.53\{0.12\}$ & & & \\
\hline & 2050 (NASA) & & & & $0.55\{0.10\}$ & & & \\
\hline & 2070 (Hadley) & & & & $0.54\{0.11\}$ & & & \\
\hline & 2070 (NASA) & & & & $0.53\{0.13\}$ & & & \\
\hline
\end{tabular}

*Significant at $p<0.001$

${ }^{a}$ Excluded parameters with high correlation to avoid over-fitting

${ }^{b}$ Estimated using 12, 65 and 44 test and background points each for Malaria, An. darlingi and An. nuneztovari respectively 
between sensitivity and specificity [78, 80]. A good model is expected to accurately predict a high proportion of test sites by having a low omission rate or high sensitivity [81]. However, because it possible for a model to have high sensitivity (low omission rate) just by predicting species presence in large parts of the area of interest, we evaluated the statistical significance of the omission rate obtained using the exact one-tailed binomial test (because of the small size of the test data) [82, 83]. The acceptability of the omission rate is determined by comparing the observed rate to theoretical expectations [84]. For instance, ideally in a model where the threshold is the $10^{\text {th }}$ percentile presence, approximately $10 \%$ omission is theoretically expected. Omission rates higher than this value therefore indicate overfitting [84]. In our study, we used the ETSS as our threshold, therefore omission rates less than the ETSS value for each model are acceptable. Finally, because the AUC has been criticized as assessing the degree to which predictors can restrict species range rather than model performance $[83,85]$, we employed the true skill statistic (TSS) as a further test of model performance. The true skill statistic is the mean of net prediction success rate for presence and absence $[83,86]$. Although TSS takes into account omission and commission errors, it avoids reliance on prevalence or size of validation set, and is thus a good measure of predictive accuracy of presence-only models [85]. TSS values also range from 0 to 1 , with values $>0.6$ considered good, $>0.7$ very good [87]

\section{Limitations}

Although modeling P. falciparum and P. vivax distributions separately may have been more informative, with the possibility of directing interventions specific to each parasite species [88], our data access was limited to pooled malaria data in which the infections were not distinctly identified. However, of the two parasites, modeling $P$. vivax distribution may have been more arduous given its latent hypnozoite stage [88], which may be difficult to account for in our models, especially for the future scenarios. We also assumed a constant rate of deforestation in our LULC model and that deforestation and climate change are independent, which may be unrealistic given the number of studies that have linked deforestation with global and regional climate change [89, 90]. Finally, we had no information on detection probability, i.e., the probability of a species being detected given that it occupies a location (occurrence probability) and that sampling was conducted in that location [91]. This probability often varies with the same covariates that determine occurrence probability [92], and when not separated from occurrence probability, may under- or over-estimate model results [92]. Thus, we ask readers to exercise caution in interpreting model results.

\section{Results}

\section{LULC changes}

The LCM outputs for LULC changes in 2050 and 2070 are presented in Additional file 2. The maps indicate that at current rates of deforestation, large parts of the Amazon forest, particularly in the interior and the South would be lost by the mid-century, assuming a businessas-usual scenario in which deforestation progresses at approximately the same rate as over the past decade. Most of the loss is expected along transportation routes (roads and rivers) as the interior opens up to urbanization and infrastructural developments. Forest loss would also increase in the South, particularly in Beni and Santa Cruz (Bolivia), Mato Grosso, Rondônia, Pará, Maranhão and Tocantins (in Brazil, particularly due to soy plantations), along the coasts of Guyana, French Guiana and Suriname. Nonforest areas, such as the savanna between Roraima (Brazil) and Bolivar (Venezuela) are also expected to expand by 2050 and 2070. While our results are similar to those previously published [93], we advise caution in the interpretation as the change pattern in the interior closely follows the drivers of LULC change we employed. Altogether, our forecast indicates an estimated $780,000 \mathrm{~km}^{2}$ of forests would be lost area by 2070 (Table 2), a development that may have an impact on vector and malaria distribution in the region.

\section{Habitat suitability modeled using current conditions}

Predictive maps of habitat suitability using current conditions are presented in Fig. 2. For malaria, areas of relatively high habitat suitability (high $=0.5-0.75$; very high $0.75-1$ ) are predicted within the interior of the Amazon in Brazil, along the coasts of the Guianas, along the Pacific coast of Colombia and in western Venezuela, covering a total land area of about $672,000 \mathrm{~km}^{2}$. Zones of moderate habitat suitability $(0.25-0.5)$ are predicted in the Amazonian regions of Peru, Bolivia and Colombia while the rest of the study area, including the Andes and the Brazilian highlands have low habitat suitability $(<0.25)$. Elevation was the biggest contributor to the model (45.6\%), followed by precipitation of the driest quarter (16.3\%), mean temperature of the coldest month $(12.9 \%)$ and precipitation of the driest month (9\%). Population (0.1 \%) and LULC (0.2 \%) did not contribute to the model (Additional file 3 for response curves and jackknife of variable importance). The model had excellent discriminatory power as indicated by the test

Table 2 Summary statistics of projected changes in LULC

\begin{tabular}{|c|c|c|c|c|}
\hline \multirow[t]{2}{*}{ Year } & \multicolumn{2}{|c|}{ Category $\left(\mathrm{Km}^{2}\right)$} & \multirow[t]{2}{*}{ Period } & \multirow{2}{*}{$\begin{array}{l}\text { Change } \\
\left(\mathrm{Km}^{2}\right)\end{array}$} \\
\hline & Forested & Deforested & & \\
\hline 2010 & 6432680 & 5903650 & $2010-2050$ & -699475 \\
\hline 2050 & 5733205 & 6603125 & 2010-2070 & -777265 \\
\hline 2070 & 5655415 & 6680915 & $2050-2070$ & -77790 \\
\hline
\end{tabular}




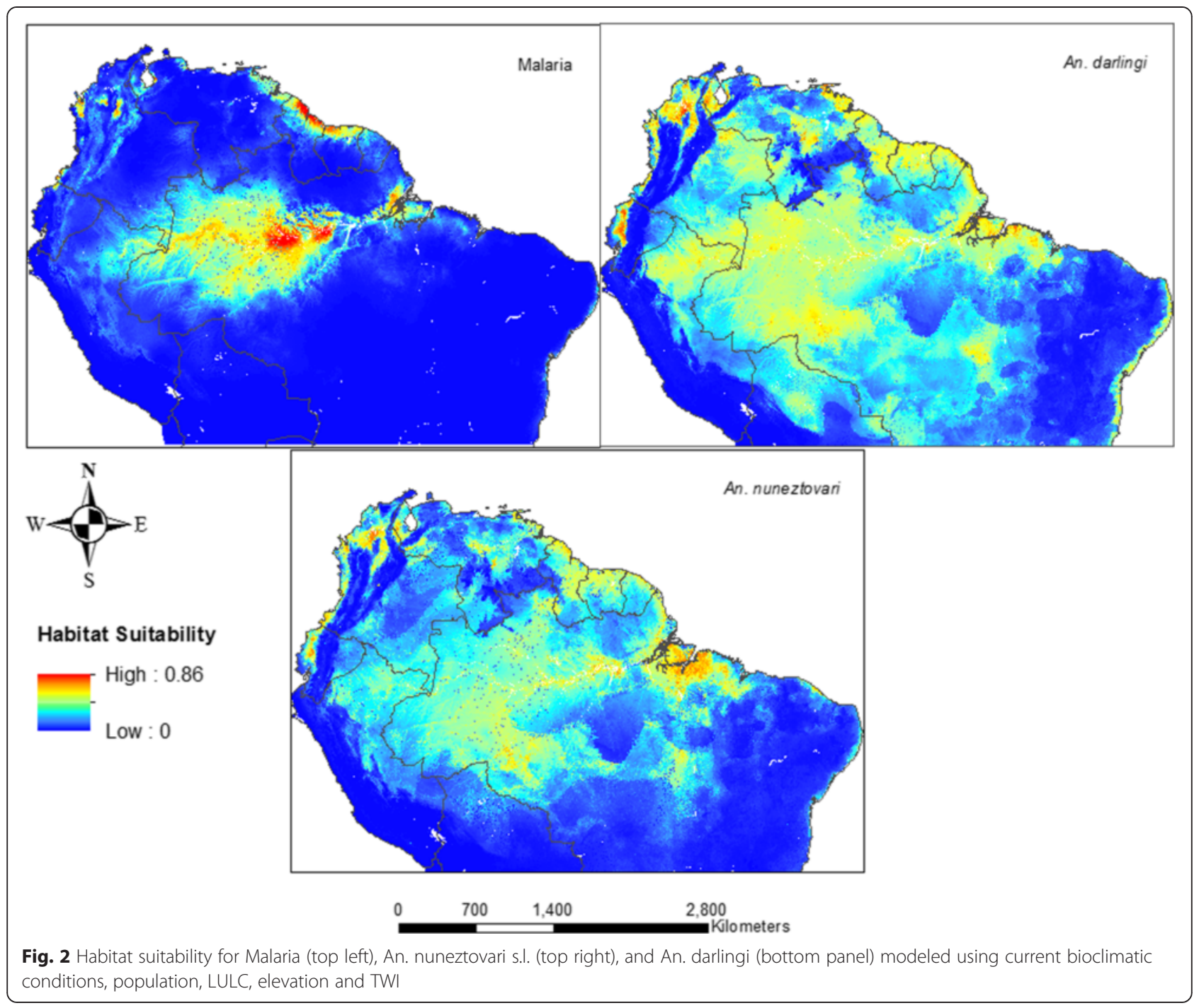

AUC (0.90) (Table 1). The mean values of the test points and ETSS were relatively moderate, as was the omission rate showing that a reasonable proportion of the test sites were correctly predicted. The reported TSS value of 0.57 also showed a fair indication of the model performance.

Model results for An. nuneztovari s.l. show areas of relatively high habitat suitability along the coast of Ecuador, the Pacific coast and the Llanos of Colombia, western Venezuela, the coasts in the Guiana Shield, and the states of Pará, Mato Grosso and Amazonas in Brazil, occupying about $460,000 \mathrm{~km}^{2}$ of land area. Relatively moderate to low $(<0.5)$ suitability are shown in other parts of Colombia, Peru, Bolivia, Venezuela and the rest of Brazil. As expected, the presence of this vector is not predicted in the Andes where high altitudes prevail. Elevation was the most important predictor for this species (33.4\%), followed closely by temperature seasonality (30\%) and annual precipitation (13.9 \%). Population (8.7 \%) and LULC (4.4\%) also contributed marginally to the model (Response curves in Additional file 4). The surface depicting An. nuneztovari s.l. habitat suitability (Fig. 2) clearly distinguished between presence and absence sites $(A U C=0.79)$, had a good TSS value (0.68) and a moderate omission rate $(0.30)$ (Table 1 ).

Relatively high suitability were reported for An. darlingi in areas such as the interior of Ecuador, the Pacific and Caribbean coasts of Colombia, the Llanos, western and coastal Venezuela, the coasts of the Guianas, the Amazonian states in Brazil and Loreto in Peru, an area of approximately $920,000 \mathrm{~km}^{2}$. Moderate suitability was predicted in the other parts of the study area except the Andean mountains, the Brazilian Highlands and a few patches within the Amazon where probabilities are low. Elevation alone accounted for $53.3 \%$ of the model while annual precipitation (18.4\%) and population (11\%) were the next biggest contributors. Precipitation seasonality (7.9\%) was a marginal contributor whereas LULC did not influence the model (Additional file 5). This suggests 
a limitation of the Maxent model rather than lack of influence from land cover and land use, as Fuller et al. [65] found that Maxent sometimes produced unrealistic results when categorical land cover maps were used as covariates. This model had fair discriminatory power (AUC $=0.75)$, a fair TSS value $(0.58)$ and moderate omission rate.

\section{Habitat suitability modeled using predicted future conditions \\ Malaria}

Figure 3 reveals the projected distributions for malaria in the years 2050 and 2070 using the NASA and Hadley center climate models. As shown, the foci of malaria are expected to remain in the interior of the Amazon, along the coasts in the Guiana Shield, in northern Colombia and along the southern border of Colombia and Venezuela. Moderate habitat suitability $(0.25-0.5)$ was predicted mostly around North-western Brazil, eastern Peru and South-western Colombia in the NASA model while the
Hadley model prediction included more regions in the Amazon and Bolivia. However, total land area of suitability is expected to decrease compared with current distributions, except with the 2050 Hadley model. By 2050, the NASA model predicts a $28 \%$ reduction in suitable area whereas a $3 \%$ increase is estimated from the Hadley center model.

By 2070 however, the area is expected to have decreased by 6 and $17 \%$ according to the Hadley and NASA models, respectively, compared with the current distribution. The NASA model is less conservative, predicting lesser areas of malaria presence by 2050 and 2070, but bigger changes. When the gains and losses in each habitat suitability category were analyzed for the future predictions (see Additional file 6), only areas of low suitability reduced in area $\left(\sim 129,000 \mathrm{~km}^{2}\right)$ between 2050 and 2070 whereas the other categories gained in the NASA model. With the Hadley model, areas of low and very high suitability increased in area $\left(\sim 33,000 \mathrm{~km}^{2}\right.$ and $27,000 \mathrm{~km}^{2}$ respectively) while medium and high suitability had losses.

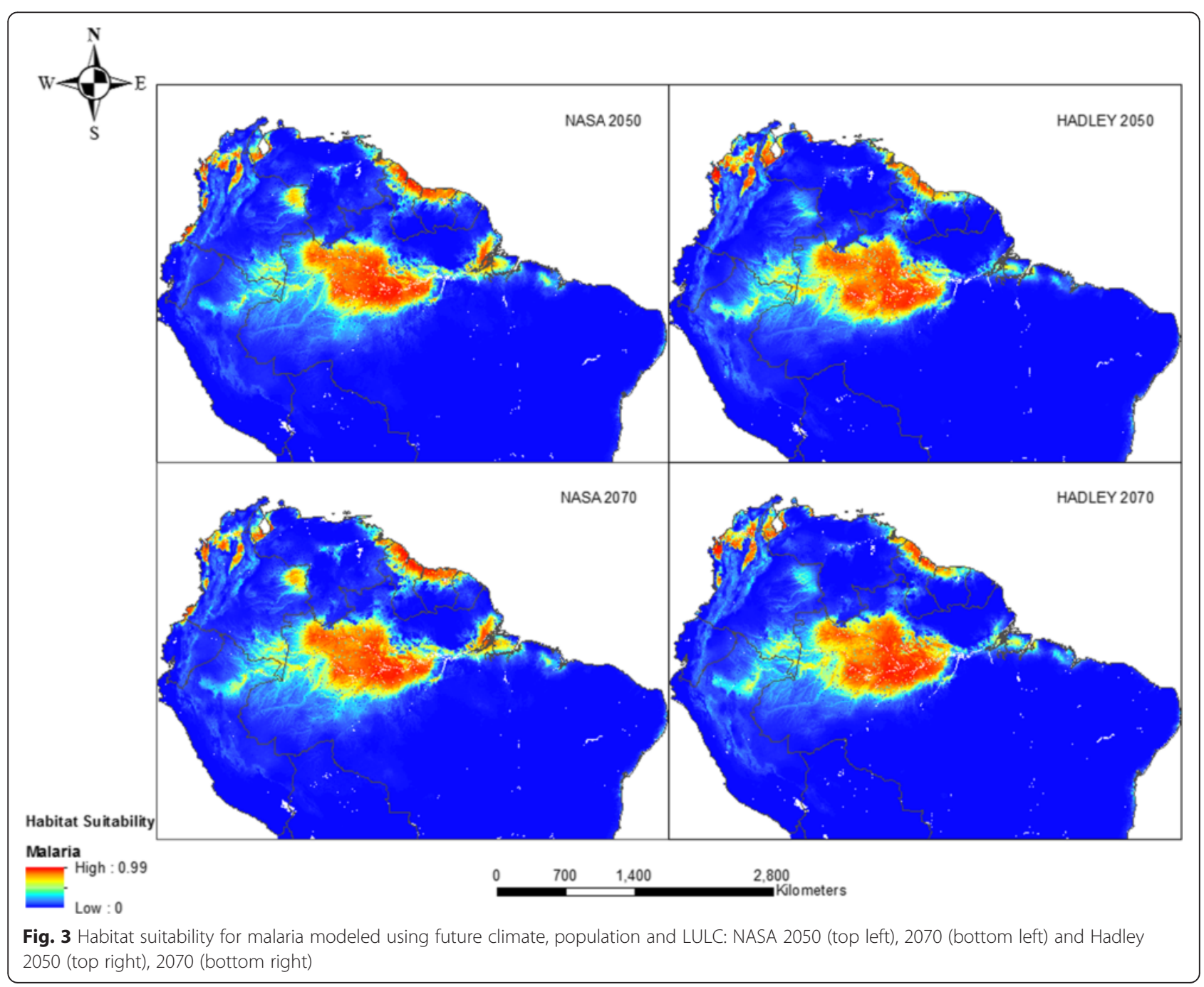


The full cross-tabulation of current and future distributions of malaria is presented in (Additional file 7). Maxent predicted a range contraction within the Amazon, in the coast of Guyana, Antioquia and Choco in Colombia, and around the northern border between Colombia and Venezuela. Range expansion was predicted around the border of Brazil, Colombia and Peru and in south-east Colombia.

\section{Anopheles nuneztovari s.l.}

Areas of relatively high habitat suitability for An. nuneztovari s.l. are predicted along rivers in the Amazon, the coasts in the eastern part of the study area, and in patches in Venezuela and Colombia from both models for 2050 (Fig. 4). Most of the Amazon, eastern Brazil and middle belt of Colombia and Venezuela have moderate probabilities of vector presence. Both the Hadley and NASA models forecast a 5 and $20 \%$ increase in range respectively by 2050 . It is noteworthy that though the species was mostly absent around the Andes with current conditions, its presence in this area is predicted by 2050 . The range is expected to increase by $14 \%$ in 2070 according to the Hadley model whereas a $10 \%$ increase is projected by NASA model. During this period, the Llanos, southern Colombia, eastern Peru, Pacific and Caribbean coasts of Colombia and large parts of the Amazon have medium predicted probabilities as estimated by the Hadley model whereas most of the Llanos are excluded in the NASA model.

As with the malaria model, only areas of low suitability in the NASA model decreased in size $\left(\sim 232,100 \mathrm{~km}^{2}\right)$ when gains and losses were analyzed between the 2050 and 2070 models. On the other hand, moderate and high suitability areas gained, while low and very high suitability areas lost in the Hadley model for the same period (Additional file 6). An. nuneztovari s.l. range is shown to expand in the Amazon interior possibly along transportation routes, and along the coast in the Guianas according to NASA model (see Additional file 8). A similar pattern is observed along the coast in the Hadley model

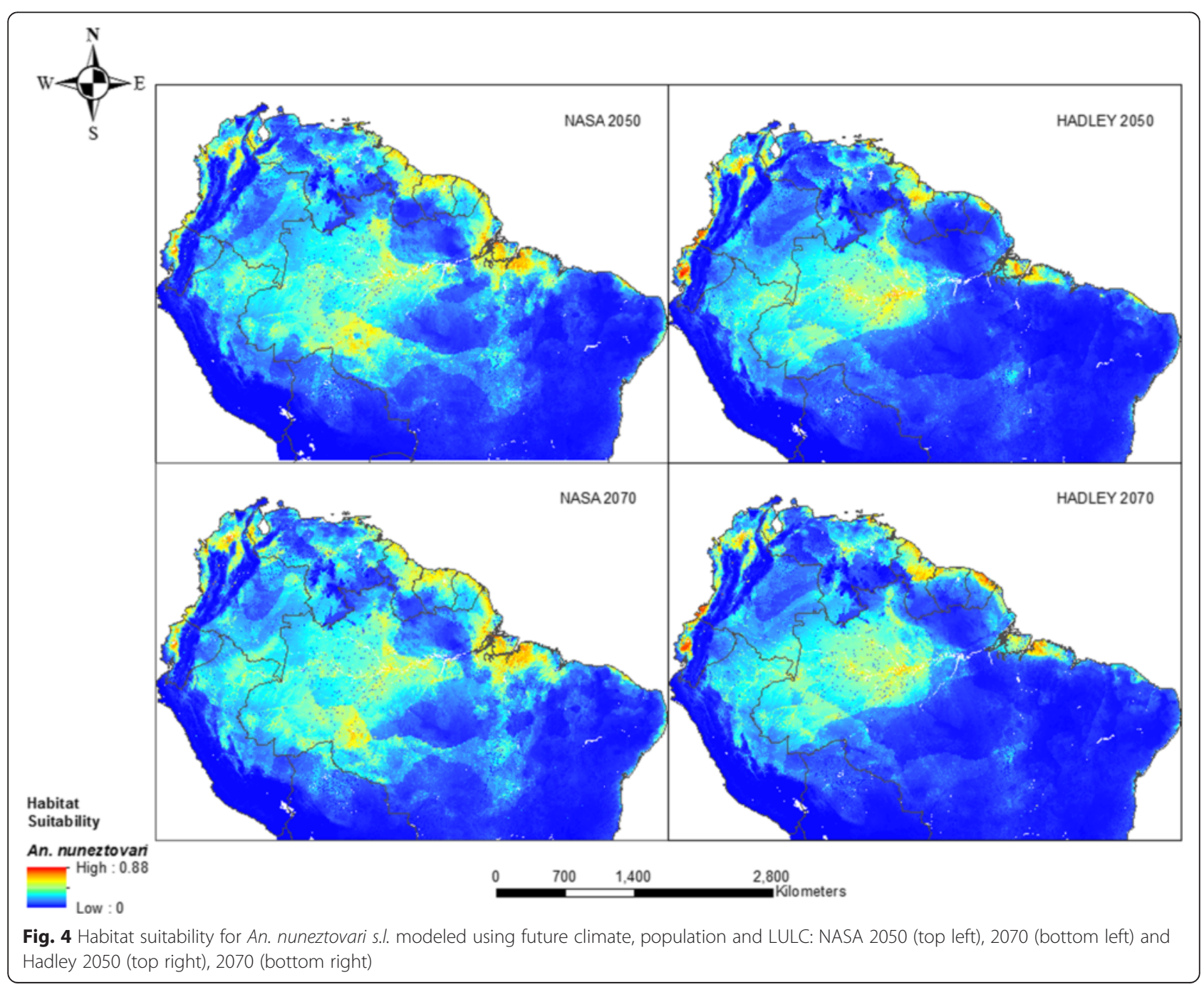


with additional areas in parts of Brazil and at the border of Venezuela and Colombia. Range contraction is mostly expected around Pará in Brazil, along the Pacific coast of Ecuador and Colombia, and in northern Colombia by both periods.

\section{Anopheles darlingi}

Most parts of the study area are expected to remain favorable to An. darlingi presence by 2050 and 2070 according to model predictions (Fig. 5). Areas of relatively high suitability are mostly found along the coasts in Ecuador, Colombia, the Guianas and Brazil. Other patches are in the Amazonian regions of Colombia, Peru and Brazil whereas moderate suitability was estimated mainly in the Amazon, Venezuela and the Guianas. While the Hadley model predicts a slight reduction in land area by 2050 and 2070 , the NASA model estimates no decline in range by 2050 but a $3 \%$ increase by 2070 .

Again, areas of moderate, high and very high suitability gained in area between 2050 and 2070 in the NASA model whereas only low suitability areas $\left(\sim 107,000 \mathrm{~km}^{2}\right)$ gained in the Hadley model for same period (see Additional file 6). Range contraction is predicted for An. darlingi in patches around Rondônia, the Amazon states in Brazil, Colombia and Peru, and Apure and Bolivar in Venezuela (Additional file 9). Expansion is expected in a few areas around Bolivia, Brazil, Colombia and the Guianas.

\section{Discussion}

Our study is unique in that it investigates the influence of climate, LULC and population changes on potential distributions of the malaria parasites, An. darlingi, and An. nuneztovari s.l. in NSA. We applied the presence-only Maxent model to project the current and future spatial distribution of malaria parasites and mosquito vector species, highlighting the potential environmental drivers of changes in their ranges. The relatively moderate-to-high AUC values for An. darlingi, malaria and An. nuneztovari s.l. respectively not only reveal the model's ability to distinguish presence and absence sites [76], but also the

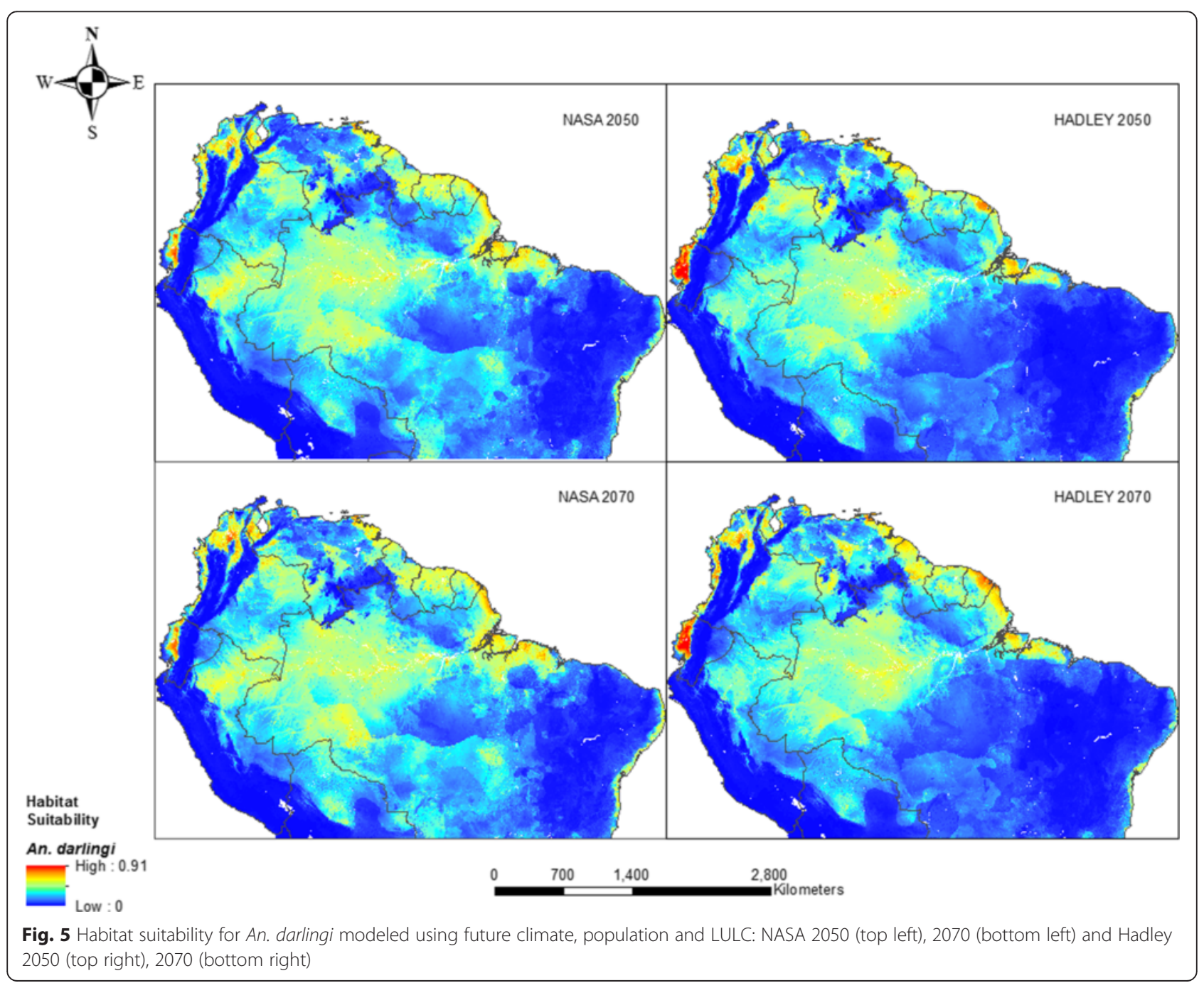


higher chance of occurrence points being given relatively higher probabilities of presence compared to pseudoabsence points [73]. The TSS values reported also indicate that our models were fairly accurate in predicting the presence and absence of the species by keeping false positives and negatives to a minimum [83]. When the ability of the models to predict test sites was evaluated, they were relatively sensitive with significantly moderate omission rates, indicating that many of the test points fall into areas predicted present by the models [81, 82], even as the mean probabilities of the test points were moderate as well.

The maps produced based on current conditions for both vectors and malaria parasites to a large extent agree with other studies. Our modeled potential distribution of An. darlingi and An. nuneztovari s.l. are consistent with previously published work by Sinka et al. [13], except for areas of slight divergence around the Brazilian Highlands, and parts of the Andes and the Pacific coast in Ecuador and Colombia for An. darlingi and An. nuneztovari s.l. The malaria map differs from earlier published extent of endemicity by Gething et al. $[16,17]$ mostly because our occurrence points are from one state within the Amazon and combine both parasites. However, the model accurately predicts core areas of high malaria incidence within the sub-region where control efforts should be focused. Moreover, current malaria interventions such as vector control were not considered in the model development. Thus, taking into account the possibility of anophelism without malaria (i.e., the occurrence of Anopheles vectors in an area/region without malaria $[94,95]$ as was discovered in Europe for the species complex, An. maculipennis [96] and may be the case with An. nuneztovari species complex in the Brazilian Amazon [28]), it is highly plausible that the actual extent of malaria is limited to areas of known incidence in the region, rather than where vectors may be found. Moreover, a map depicting probability of vector presence does not necessarily imply risk of the parasites it transmits [95].

When projected on future climatic and human-induced changes, model simulations generally showed a decrease in malaria extent by 2050 and 2070. The areas of range contraction for malaria (in Brazil, Guyana and Colombia) in particular bolster optimism as these are currently the localities with some of the highest malaria incidence in the region $[12,97,98]$. These results are especially informative when considering the renewed drive towards malaria elimination in the region [99]. Although the area extent for the vectors are projected to increase, the decrease in malaria extent despite this implies that the interplay of climatic, population and local land use patterns can naturally force a decline in malaria incidence [71]. For example, development may lead to lower malaria as more infrastructure and better living conditions become available, while climate change and deforestation produce range expansion of vectors. The spatial extent of malaria may decrease even further as principles of integrated vector management (IVM) become more entrenched in vector control programs [100], surveillance and monitoring are sustained, more efficient and effective drugs and vector control measures become available, and malaria treatment become more accessible [7]. Elimination in this region by 2050 may be feasible as strategies outlined by Feacham [101], such as development of new drugs, vaccines, and insecticides and strengthening national and regional collaborations are executed. Unsurprisingly, measures of precipitation and temperature as well as elevation were the highest predictors of malaria in the region as found in several previous studies [102-104]. The impacts are especially important as other studies have shown that climate change leads to warmer and drier conditions, which may aid mosquito and parasite development, and thus potentially increase malaria risk, even in highland areas [9].

Future projections reveal a modest increase for $A n$. darlingi and a slightly larger range expansion for $A n$. nuneztovari s.l. by 2050 and 2070. The areas of range expansion and contraction for both species are likely to be influenced by human activities as more parts of the Amazon become urbanized, infrastructural projects increase [12] and gold mining continues [105]. This is especially important as change in LULC was a predictor for $A n$. nuneztovari s.l., consistent with earlier reports of the species colonizing altered environments and being associated with deforestation [29-32, 98]. Surprisingly, LULC was not a predictor for $A n$. darlingi in our models despite numerous studies indicating a correlation between the species and land cover or deforestation [9, 10, 12, 29-32, 98]. Population density was shown as an important predictor for An. darlingi and a marginal predictor for An. nuneztovari s.l., consistent with their known behavior $[5,9]$ and that of other species such as Culex pipiens (Linnaeus 1758) [73]. Elevation was the most important predictor of both species and malaria for all models. Such a result was expected considering that recent studies have reported some other mosquito species at higher altitudes than regularly found, for example in Ecuador [106] and projected for parts of Mesoamerica in 2080 [22]. Moreover, malaria has been reported in highland areas of Bolivia [107] and some East-African countries [102, 108, 109], so vectors must be present for transmission. Finally, our results are in agreement with the current understanding of climate interaction with mosquitoes; i.e., temperature and precipitation were major contributors to the projected vector distributions for all climate scenarios. This is supported by other studies that have established associations between temperature, precipitation and both An. darlingi and An. nuneztovari s.l. $[12,13,98]$. These variables have also been linked to other Anopheles species [102, 110-112], and to An. albimanus [22] and An. arabiensis [65, 71] in future periods. 


\section{Conclusion}

We presented models of the current and future spatial distribution of malaria, An. darlingi, and An. nuneztovari s.l. in NSA using bioclimatic, topographic, hydrologic, LULC and population data. Our analyses reveal that while climatic factors, temperature and precipitation, play important roles in current and future distribution of malaria parasites, An. darlingi, and An. nuneztovari s.l. in the region, aspects of human influence measured by LULC and population changes will also affect the distribution of $A n$. nuneztovari s.l. and An. darlingi respectively. As such, stricter regulations need to be enforced and sustained to reduce further deforestation in the Amazon. Although the models project increased range for the vectors, sustained vector control as well as deployment of novel strategies in the near future could prevent this expansion. Based on the factors analyzed, malaria extent is expected to naturally decrease in the future. Thus, with increased implementation of IVM strategies and more effective anti-malaria drugs, trajectories of climate change and deforestation may complement efforts underway to achieve the goal of malaria elimination in NSA in the coming decades.

\section{Additional files}

Additional file 1: Differences in annual precipitation between current and future conditions. NASA 2050 (top left), 2070 (bottom left) and Hadley 2050 (top right), 2070 (bottom right). (TIFF 24678 kb)

Additional file 2: Projected LULC changes obtained using LCM: 2010 (top panel), 2050 (middle panel), and 2070 (bottom panel). (TIFF $24675 \mathrm{~kb}$ )

Additional file 3: Response curves of Malaria model to: (A) Elevation (srtm); (B) Precipitation of the driest quarter (bio 17); (C) Mean temperature of the coldest month (bio 6); (D) Precipitation of the driest month (bio 14); and (E) Jacknife of variable importance (Red bar shows the gain when all variables are used. The light blue bar shows the gain when a specific variable is excluded from analysis, a lower gain indicating that the specific variable has more information not contained in other variables. The dark blue bar indicates gain when the specific variable is used in isolation). (PDF $257 \mathrm{~kb}$ )

Additional file 4: Response curves of An. nuneztovari model to: (A) Elevation (srtm); (B) Temperature seasonality (bio 4); (C) Annual precipitation (bio 12); (D) Population; (E) LULC; and (F) Jacknife of variable importance (Red bar shows the gain when all variables are used. The light blue bar shows the gain when a specific variable is excluded from analysis, a lower gain indicating that the specific variable has more information not contained in other variables. The dark blue bar indicates gain when the specific variable is used in isolation) (PDF $258 \mathrm{~kb}$ )

Additional file 5: Response curves of An. darlingi model to: (A) Elevation (srtm); (B) Annual precipitation (bio 12); (C) Population; (D) Precipitation seasonality (bio 15); and (E) Jacknife of variable importance (Red bar shows the gain when all variables are used. The light blue bar shows the gain when a specific variable is excluded from analysis, a lower gain indicating that the specific variable has more information not contained in other variables. The dark blue bar indicates gain when the specific variable is used in isolation). (PDF $255 \mathrm{~kb}$ )

Additional file 6: Analysis of gains and losses in area between 2050 and $\mathbf{2 0 7 0}$ models. From left to right: Malaria (NASA (top), Hadley (bottom)), An. darlingi (NASA (top), Hadley (bottom)), An. nuneztovari (NASA (top), Hadley (bottom)). (TIFF 310086 kb)
Additional file 7: Cross-tabulation of present and future distribution to show likely shifts in Malaria habitat suitability: NASA 2050 (top left), 2070 (bottom left) and Hadley 2050 (top right), 2070 (bottom right). (TIFF $2525 \mathrm{~kb}$ )

Additional file 8: Cross-tabulation of present and future distribution to show likely shifts in An. nuneztovari s.l. habitat suitability: NASA 2050 (top left), 2070 (bottom left) and Hadley 2050 (top right), 2070 (bottom right). (TIFF $24676 \mathrm{~kb}$ )

Additional file 9: Cross-tabulation of present and future distribution to show likely shifts in An. darlingi habitat suitability: NASA 2050 (top left), 2070 (bottom left) and Hadley 2050 (top right), 2070 (bottom right). (TIFF $24677 \mathrm{~kb}$ )

\section{Abbreviations}

LULC: Land use and land cover; NSA: northern South America; SDM: Species distribution models; GCM: General circulation models; IPCC: Intergovernmental panel on climate change; NASA: National Aeronautics and Space Agency; GISS: Goddard Institute for Space Studies; RCP: Representative concentration pathways; SRTM: Shuttle Radar Topographic Mission; TWI: Topographic wetness index; MODIS: Moderate Resolution Imaging Spectrometer; IGBP: International Geosphere-Biosphere Programme; LCM: Land change modeler; AUC: Area under the curve; TSS: True skill statistic; IVM: Integrated vector management.

\section{Competing interests}

The authors declare that they have no competing interests.

\section{Authors' contributions}

TOA, DOF and JCB conceptualized the idea for the manuscript and wrote the draft. TOA conducted the analyses. WAQ, SVH, MAH, MLQ and MVGL contributed to the revision of the manuscript. All authors read and approved the final manuscript.

\section{Acknowledgements}

The research was supported by NIH ICEMR grant: Centro Latino Americano de Investigación en Malaria (CLAIM) sponsored by NIAID/ICEMR (U19A1089702), Colciencias (719-2013). MVGL is a research fellow from CNPq. The authors also thank the two anonymous reviewers whose comments helped improve this paper.

\section{Author details}

${ }^{1}$ Abess Center for Ecosystem Science and Policy, University of Miami, Coral Gables, Florida, USA. ²Department of Geography and Regional Studies, University of Miami, Coral Gables, Florida, USA. ${ }^{3}$ Department of Public Health Sciences, Miller School of Medicine, University of Miami, Miami, Florida, USA. ${ }^{4}$ Centro de Investigación Científica Caucaseco, Cali, Colombia. ${ }^{5}$ School of Health, Valle State University, Cali, Colombia. ${ }^{6}$ Department of Public Health, Universidad Nacional de Colombia, Bogota, Colombia. ${ }^{7}$ Fundação de Medicina Tropical Dr Heitor Vieira Dourado, Manaus, Amazonas, Brazil. ${ }^{8}$ Instituto de Pesquisa Leônidas \& Maria Deane (FIOCRUZ Amazonas), Manaus, Amazonas, Brazil.

Received: 25 May 2015 Accepted: 5 August 2015

Published online: 20 August 2015

\section{References}

1. The Economist. Latin America's economies: Life after the commodity boom. March 29, 2014. http://www.economist.com/news/americas/ 21599782-instead-crises-past-mediocre-growth-big-riskunless-productivityrises-life. Accessed 7 April 2015.

2. Food and Agriculture Organization of the United Nations. Livestock's role in deforestation. http://www.fao.org/agriculture/lead/themes0/deforestation/ en/ Accessed 7 April 2015

3. Olson SH, Gangnon R, Silveira GA, Patz JA. Deforestation and malaria in Mâncio Lima County, Brazil. Emerging Infect Dis. 2010;16:1108-15.

4. Wood CH, Skole DL. Linking satellite, census, and survey data to study deforestation in the Brazilian Amazon. In: Liverman D et al., editors. People and Pixels. Washington, DC: National Academies Press; 1998. p. 70-93.

5. Vittor AY, Pan W, Gilman RH, Tielsch J, Glass G, Shields T, et al. Linking deforestation to malaria in the Amazon: characterization of the breeding 
habitat of the principal malaria vector, Anopheles darlingi. Am J Trop Med Hyg. 2009;81:5-12.

6. Hahn MB, Gangnon RE, Barcellos C, Asner GP, Patz JA. Influence of deforestation, logging, and fire on malaria in the Brazilian Amazon. PLoS One. 2014;9(1):e85725. doi:10.1371/journal.pone.0085725.

7. Herrera S, Quiñones ML, Quintero JP, Corredor V, Fuller DO, Mateus JC, et al. Prospects for malaria elimination in non-Amazonian regions of Latin America. Acta Trop. 2012;121:315-23.

8. World Health Organization. World malaria report. Geneva: WHO Press; 2014

9. Tadei WP, Thatcher BD, Santos JMH, Scarpassa VM, Rodrigues IB, Rafael MS. Ecologic observations on anopheline vectors of malaria in the Brazilian Amazon. Am J Trop Med Hyg. 1998;59:325-35.

10. Vittor AY, Gilman RH, Tielsch J, Glass G, Shields T, Lozano WS, et al. The effect of deforestation on the human-biting rate of Anopheles darlingi, the primary vector of falciparum malaria in the Peruvian Amazon. Am J Trop Med Hyg. 2006;74(1):3-11.

11. Patz JA, Olson SH. Malaria risk and temperature: influences from global climate change and local land use practices. PNAS. 2006;103(15):5635-6.

12. Hiwat H, Bretas G. Ecology of Anopheles darlingi root with respect to vector importance: a review. Par Vect. 2011;4:177.

13. Sinka ME, Rubio-Palis Y, Manguin S, Patil AP, Temperley WH, Gething PW, et al. The dominant Anopheles vectors of human malaria in the Americas: occurrence data, distribution maps and bionomic précis. Par Vect. 2010;3:72.

14. Manguin S, Carnevale P, Mouchet J, Coosemans M, Julvez J. RichardLenoble D, Sircoulon J. Biodiversity of malaria in the world. John Libbey Eurotext: Montrouge, France; 2008.

15. de Arruda M, Carvallo MB, Nussenzweig RS, Maracic M, Ferreira AW, Cochrane $\mathrm{AH}$. Potential vectors of malaria and their different susceptibility to Plasmodium falciparum and Plasmodium vivax in northern Brasil identified by immunoassay. Am J Trop Med Hyg. 1986;35:873-81.

16. Gething PW, Patil AP, Smith DL, Guerra CA, Elyazar IR, Johnston GL, et al. A new world malaria map: Plasmodium falciparum endemicity in 2010. Malar J. 2011;10:378.

17. Gething PW, Elyazar IR, Moyes CL, Smith DL, Battle KE, Guerra CA, et al. A long neglected world malaria map: Plasmodium vivax endemicity in 2010. PLoS Negl Trop Dis. 2011;6(9):e1814

18. Foley DH, Weitzman AL, Miller SE, Faran ME, Rueda LM, Wilkerson RC. The value of georeferenced collection records for predicting patterns of mosquito species richness and endemism in the Neotropics. Ecol Entomol. 2008;33:12-23.

19. Osborn FR, Rubio-Palis Y, Herrera M, Figuera A, Moreno J. Caracterizacion ecoregional de los vectores de malaria en Venezuela. Bol Mal Salud Amb. 2004:44:77-92.

20. Rubio-Palis Y, Zimmerman RH. Ecoregional classification of malaria vectors in the neotropics. J Med Entomol. 1997:34:499-510.

21. Loaiza JR, Bermingham E, Scott ME, Rovira JR, Conn JE. Species composition and distribution of adult Anopheles (Diptera: Culicidae) in Panama. J Med Entomol. 2008;45:841-51.

22. Fuller DO, Ahumada ML, Quiñones ML, Herrera S, Beier JC. Near-present and future distribution of Anopheles albimanus in Mesoamerica and the Caribbean Basin modeled with climate and topographic data. Int J Health Geogr. 2012;11:13.

23. Roll Back Malaria Partnership. Global Malaria Action Plan for a malaria free world. Geneva: WHO Press; 2008.

24. Pan American Health Organization. Programa Regional de Acción y Demostración de Alternativas Sostenibles para el Control de Vectores de la Malaria sin Uso de DDT en México y América Central, Mexico. Washington DC: PAHO; 2008.

25. Zimmerman $\mathrm{RH}$. Ecology of malaria vectors in the Americas and future direction. Mem Inst Oswaldo Cruz. 1992;87 Suppl 111:371-83.

26. Fritz GN, Conn J, Cockburn A, Seawright J. Sequence analysis of the ribosomal DNA internal transcribed spacer 2 from populations of Anopheles nuneztovari s.l. (Diptera: Culicidae). Mol Biol Evol. 1994;11:406-16.

27. Calado DC, Foster PG, Bergo ES, dos Santos CL, Galardo AK, Sallum MA Resurrection of Anopheles goeldii from synonymy with Anopheles nuneztovari (Diptera: Culicidae) and a new record for Anopheles dunhami in the Brazilian Amazon. Mem Inst Oswaldo Cruz. 2008;103:791-9.

28. Deane LM. Malaria vectors in Brazil. Mem Inst Oswaldo Cruz. 1986;81:5-14.

29. Nagm L, Luitgards-Moura JF, Neucamp CD, Monteiro-de-Barros FS, Honorio NA, Tsouris $P$, et al. Affinity and diversity indices for anopheline immature forms. Rev Inst Med Trop Sao Paulo. 2007;49:309-16.
30. Manguin S, Roberts DR, Andre RG, Rejmankova E, Hakre S. Characterization of Anopheles darlingi (Diptera: Culicidae) larval habitats in Belize, Central America. J Med Entomol. 1996;33:205-11.

31. da Silva-Vasconcelos A, Kato MY, Mourao EN, de Souza RT, Lacerda RN, Sibajev A, et al. Biting indices, host-seeking activity and natural infection rates of anopheline species in Boa Vista, Roraima, Brazil from 1996 to 1998. Mem Inst Oswaldo Cruz. 2002;97:151-61.

32. Moreno JE, Rubio-Palis Y, Acevedo P. Identificación de criaderos de anofelinos en un área endémica del estado Bolívar, Venezuela. Bol Malariol San Amb. 2000;40:21-30.

33. Elith J, Graham C, Anderson R, Dudik M, Ferrier S, Guisan A, et al. Novel methods improve prediction of species' distributions from occurrence data. Ecography. 2006;29:129-51.

34. Williams JN, Seo CW, Thorne J, Nelson JK, Erwin S, et al. Using species distribution models to predict new occurrences for rare plants. Div \& Dist. 2009;15:565-76.

35. Machado-Machado EA. Empirical mapping of suitability to dengue fever in Mexico using species distribution modeling. App Geo. 2012;33:82-93.

36. Mischler P, Kearney M, McCarroll JC, Scholte RGC, Vounatsou P, Malone JB. Environmental and socio-economic risk modelling for Chagas disease in Bolivia. Geospat Health. 2012;6(3):S59-66.

37. VectorMap. http://www.vectormap.org. Accessed 22 Sept 2013.

38. Global Biodiversity Information Facility. http://www.gbif.org/ Accessed 23 Sept 2013

39. Foley DH, Wilkerson RC, Birney I, Harrison S, Christensen J, Rueda LM. MosquitoMap and the Mal-area calculator: new web tools to relate mosquito species distribution with vector borne disease. Intl J Health Geo. 2010;9:11.

40. Montoya-Lerma J, Solarte YA, Montoya-Lerma J, Solarte YA, Giraldo-Calderón, Quiñones ML, et al. Malaria vector species in Colombia: a review. Mem Inst Oswaldo Cruz. 2011;106:223-38.

41. Charlwood JD. Biological variation in Anopheles darlingi Root. Mem Inst Oswaldo Cruz. 1996;91:391-8.

42. Moreno JE, Rubio-Palis Y, Paez E, Perez E, Sanchez V. Abundance, biting behaviour and parous rate of anopheline mosquito species in relation to malaria incidence in gold-mining areas of southern Venezuela. Med Vet Entomol. 2007:21:339-49.

43. Olano VA, Brochero H, Saenz R, Quinones ML, Molina JA. Mapas preliminaries de la distribution de species de Anopheles vectores de malaria en Colombia. Biomedica. 2001;21:402-8.

44. Achee NL, Grieco JP, Masuoka P, Andre RG, Roberts DR, Thomas J, et al. Use of remote sensing and geographic information systems to predict locations of Anopheles darlingi positive breeding sites within the Sibun River in Belize, Central America. J Med Entomol. 2006:43:382-92.

45. Roberts DR, Manguin S, Rejmankova E, Andre R, Harbach RE, Vanzie E, et al, Spatial distribution of adult Anopheles darlingi and Anopheles albimanus in relation to riparian habitats in Belize, Central America. J Vect Ecol. 2002:27:21-30

46. Rodriguez $\mathrm{MH}$. Malaria and dengue vector biology and control in Latin America. In: Knols BGJ, Louis C, editors. Bridging laboratory and field research for genetic control of disease vectors. Springer; 2006. p. 129-141.

47. Gabaldón A, Guerrero L. An attempt to eradicate malaria by weekly administration of pyrimethamine in areas of out-of-doors transmission in Venezuela. Am J Trop Med Hyg. 1959;8:433-9.

48. Tadei WP, Dutary TB. Malaria vectors in the Brazilian amazon: Anopheles of the subgenus Nyssorhynchus. Rev Inst Med Trop Sao Paulo. 2000:42:87-94.

49. Rubio-Palis Y, Curtis CF. Biting and resting behaviour of anophelines in western Venezuela and implications for control of malaria transmission. Med Vet Entomol. 1992:6:325-34.

50. Oliveira-Ferreira J, Lacerda MVG, Brasil P, Ladislau JLB, Tauil PL, Daniel-Ribeiro CT. Malaria in Brazil: an overview. Malar J. 2010;9:115.

51. Environmental Systems Research Institute. ArcGIS Desktop: Release 10.2. Redlands, CA; 2014.

52. WorldClim Global Climate database. http://www.worldclim.org/ Accessed 28 Sept 2013; 15 May 2014.

53. Hijmans RJ, Cameron SE, Parra JL, Jones PG, Jarvis A. Very high resolution interpolated climate surfaces for global land areas. Intl J Clim. 2005;25:1965-78.

54. Core Writing T, Pachauri RK, Meyer LA, editors. Climate Change 2014 Synthesis Report. Contribution of Working Groups I, II and III to the Fifth Assessment Report of the Intergovernmental Panel on Climate Change. Geneva, Switzerland: IPCC; 2014 
55. Meinshausen M, Smith SJ, Calvin K, Daniel JS, Kainuma MLT, Lamarque JF, et al. The RCP greenhouse gas concentrations and their extensions from 1765 to 2300. Clim Chang. 2011;109(1-2):213-41.

56. Stocker TF, Qin D, Plattner GK, Tignor M, Allen SK, Boschung J, et al. eds. Climate Change 2013: The Physical Science Basis. Working Group 1 (WG1) Contribution to the Intergovernmental Panel on Climate Change (IPCC) 5th Assessment Report (AR5). Cambridge, United Kingdom and New York, NY, USA: Cambridge University Press; 2013.

57. Shuttle Radar Topography Mission. Global Land Cover Facility, University of Maryland, College Park, Maryland, February 2000. http://glcf.umd.edu/data/ srtm/ Accessed 29 Aug 2013

58. Beven KJ, Kirkby MJ. A physically based, variable contributing area model of basin hydrology/Un modèle à base physique de zone d"appel variable de I"hydrologie du bassin versant. Hydrolog Sci J. 1979;24:43-69.

59. LandScan (2010) ${ }^{\mathrm{TM}}$. High Resolution Global Population Data Set copyrighted by UT-Battelle, LLC, operator of Oak Ridge National Laboratory under Contract No. DE-AC05-00OR22725 with the United States Department of Energy.

60. Patz JA, Githeko AK, McCarty JP, Hussein S, Confalonieri U, de Wet N. Climate change and infectious diseases. In: McMichael A, Campbell-Lendrum D, Corvalan C, Ebi K, Githeko A, Scheraga J, Woodward A, editors. Climate change and human health: risks and responses. Geneva: World Health Organization; 2003. p. 103-32.

61. Moderate Resolution Imaging Spectrometer (MODIS). https://pdaac.usgs.gov/ Accessed 28 Sept 2013.

62. Eastman R. Idrisi: The Selva Edition. Worcester, MA: Clark Labs; 2012.

63. Clarks Lab. The Land Change Modeler for Ecological Sustainability. Idrisi Focus paper 2009. http://www.clarklabs.org/applications/upload/ Land-Change-Modeler-IDRISI-Focus-Paper.pdf Accessed 9 April 2015

64. Digital Charts of the World. World waterbodies and roads. http://www.diva-gis.org/gdata. Accessed 22 Feb 2015.

65. Fuller DO, Parenti MS, Hassan AN, Beier JC. Linking land cover and species distribution models to project potential ranges of malaria vectors: an example using Anopheles arabiensis in Sudan and Upper Egypt. Malar J. 2012;11:264.

66. Population Reference Bureau. Population growth rates. http://www.prb.org Accessed 18 Nov 2013.

67. Phillips SJ, Dudik M, Schapire RE. A maximum entropy approach to species distribution modeling. Proceeding ICML. 2004; doi: 10.1145/1015330.1015412.

68. Elith J, Leathwick JR. Species distribution models: ecological explanation and prediction across space and time. Ann Rev Eco Evol Syst. 2009:40:677-97.

69. Syfert MM, Smith MJ, Coomes DA. The effects of sampling bias and model complexity on the predictive performance of MaxEnt species distribution models. PLoS One. 2013;8, e55158.

70. Phillips SJ, Dudík M. Modeling of species distributions with Maxent: new extensions and a comprehensive evaluation. Ecography. 2008;31:161-75.

71. Drake JM, Beier JC. Ecological niche and potential distribution of Anopheles arabiensis in Africa in 2050. Malar J. 2014;13:213.

72. Leathwick JR, Elith J, Francis MP, Hastie T, Taylor P. Variation in demersal fish species richness in the oceans surrounding New Zealand: an analysis using boosted regression trees. Mar Ecol Prog Ser. 2006;321:267-81.

73. Conley AK, Fuller DO, Haddad N, Hassan AN, Gad AM, Beier JC. Modeling the distribution of the West Nile and Rift Valley Fever vector Culex pipiens in arid and semi-arid regions of the Middle East and North Africa. Par Vect. 2014;7:289.

74. Phillips SJ, Dudık M, Elith J, Graham CH, Lehmann A, Leathwick J, et al. Sample selection bias and presence-only distribution models: implications for background and pseudo-absence data. Ecol Appl. 2009:19:181-97.

75. Phillips SJ, Anderson RP, Schapire RE. Maximum entropy modeling of species geographic distributions. Ecol Model. 2006;190:231-59.

76. Fielding AH, Bell JF. A review of methods for the assessment of prediction errors in conservation presence/absence models. Env Cons. 1997;24:38-49.

77. Fan J, Upadhye S, Worster A. Understanding receiver operating characteristic (ROC) curves: Pedagogical Tools and Methods. CJEM. 2006:8(1):19-20.

78. Liu C, Berry PM, Dawson TP, Pearson RG. Selecting thresholds of occurrence in the predictions of species distribution. Ecography. 2005;28:385-93.

79. Shcheglovitova M, Anderson RP. Estimating optimal complexity for ecological niche models: a jackknife approach for species with small sample sizes. Ecol Model. 2013;269:9-17.
80. Cantor SB, Sun CC, Tortolero-Luna G, Richards-Kortum R, Follen M. A comparison of $C / B$ ratios from studies using receiver operating characteristic curve analysis. J Clin Epidemiol. 1999;52(9):885-92.

81. Anderson RP, Gomez-Laverde M, Peterson AT. Geographical distributions of spiny pocket mice in South America: insights from predictive models. Global Ecol Biogeo. 2002;11:131-41.

82. Pearson RG, Raxworthy CJ, Nakamura M, Townsend PA. Predicting species distributions from small numbers of occurrence records: a test case using cryptic geckos in Madagascar. Biogeo. 2007;34:102-17.

83. Lobo JM, Jimenez-Valverde A, Real R. AUC: a misleading measure of the performance of predictive distribution models. Global Ecol Biogeog. 2008;17:145-51.

84. Radosavljevic A, Anderson RP. Making better MAXENT models of species distributions: complexity, overfitting and evaluation. J Biogeography. 2031:41:629-43.

85. Allouche O, Tsoar A, Kadmon R. Assessing the accuracy of species distribution models: prevalence, kappa and the true skill statistic (TSS). J Appl Ecol. 2006;43:1223-32

86. Samson DM, Archer RS, Alimi TO, Arheart KK, Impoinvil DE, Oscar R, et al. New baseline environmental assessment of mosquito ecology in northern Haiti during increased urbanization. J Vect Ecol. 2015:40(1):1-13.

87. Jones CC, Acker SA, Halpern CB. Combining local and large-scale models to predict the distributions of invasive plant species. Ecol Appl. 2010;20:311-26.

88. Noviyanti R, Coutrier F, Utami RAS, Trimarsanto H, Tirta YK, Trianty L, et al. Contrasting transmission dynamics of co-endemic Plasmodium vivax and $P$. falciparum: implications for malaria control and elimination. PLoS Negl Trop Dis. 2015:9(5):e0003739.

89. Shukla J, Nobre C, Sellers P. Amazon deforestation and climate change. Science. 1990;247:1322-5.

90. Lawrence D, Vandecar K. Effects of tropical deforestation on climate and agriculture. Nature Clim Change. 2015;5:27-36.

91. Yackulic CB, Chandler R, Zipkin EF, Royle JA, Nichols JD, Grant EHC, et al. Presence-only modelling using MAXENT: when can we trust the inferences? Methods Ecol Evol. 2013;4:236-43.

92. MacKenzie DI, Nichols JD, Royle JA, Pollock KH, Bailey LL, Hines JE. Occupancy estimation and modeling: Inferring patterns and dynamics of species occurence. USA: Academic Press; 2006.

93. Soares-Filho BS, Nepstad DC, Curran LM, Cerqueira GC, Garcia RA, Ramos CA, et al. Modelling conservation in the Amazon basin. Nature. 2006:440:520-3.

94. Fantini B. Anophelism without malaria: an ecological and epidemiological puzzle. Parassitologia. 1994;36:83-106

95. Sedda L, Morley DW, Braks MA, De Simone L, Benz D, Rogers DJ. Risk assessment of vector-borne diseases for public health governance. Pub Health. 2014;128(12):1049-58.

96. Hackett LW, Missiroli A. The natural disappearance of malaria in certain parts of Europe. Am J Epidemiology. 1931;13:57-78.

97. Fouque F, Gaborit P, Carinci R, Issaly J, Girod R. Annual variations in the number of malaria cases related to two different patterns of Anopheles darlingi transmission potential in the Maroni area of French Guiana. Malar J. 2010;9:80.

98. Naranjo-Diaz N, Altamiranda M, Luckhart S, Conn JE, Correa MM. Malaria vectors in ecologically heterogenous localities of the Colombian Pacific region. PLoS One. 2014;9(8):e103769.

99. Herrera S, Ochoa-Orozco SA, González IJ, Peinado L, Quiñones ML, Arévalo-Herrera M. Prospects for malaria elimination in Mesoamerica and Hispaniola. PLoS Negl Trop Dis. 2015;9(5):e0003700.

100. World Health Organization. Global Strategic Framework for Integrated Vector Management. Geneva: WHO Press; 2004.

101. Feachem R. Malaria 2050: from science to strategy; from evidence to eradication. Malar J. 2014;13 Suppl 1:09.

102. Siraj AS, Santos-Vega M, Bouma MJ, Yadeta D, Ruiz Carrascal D, Pascual M. Altitudinal changes in malaria incidence in highlands of Ethiopia and Colombia. Science. 2014;343(6175):1154-8.

103. Olson SH, Gangnon R, Elguero E, Durieux L, Guégan JF, Foley JA, et al. Links between climate, malaria, and wetlands in the Amazon Basin. Emerg Infect Dis. 2009;15(4):659-62.

104. Jones AE, Wort UU, Morse AP, Hastings IM, Gagnon AS. Climate prediction of El Niño malaria epidemics in north-west Tanzania. Malar J. 2007;6:162.

105. Duarte EC, Fontes CJ. Association between annual reported gold mining extraction and incidence of malaria in Mato Grosso- Brazil, 1985-1996. Rev Soc Bras Med Trop. 2002;35:665-8. 
106. Pinault LL, Hunter FF. New highland distribution records of multiple Anopheles species in the Ecuadorian Andes. Malar J. 2011;10:236

107. Rutar T, Baldomar-Salgueiro EJ, Maguire JH. Introduced Plasmodium vivax malaria in a Bolivian community at an elevation of 2,300 meters. Am J Trop Med Hyg. 2004;70:15-9.

108. Hay SI, Rogers DJ, Randolph SE, Stern SI, Cox J, Shanks D, et al. Hot topic or hot air? Climate change and malaria resurgence in East African highlands. Trends Parasitol. 2002:18:530-4.

109. Minakawa N, Omukunda E, Zhou G, Githeko A, Yan G. Malaria vector productivity in relation to the highland environment in Kenya. Am J Trop Med Hyg. 2006;75:448-53.

110. Kashiwada M, Ohta S. Modeling the spatio-temporal distribution of Anopheles mosquito based on life history and surface water conditions. Open Ecol J. 2010;3:29-40.

111. Foley DH, Linton YM, Ruiz-Lopez JF, Conn JE, Sallum MA, Póvoa MM, et al. Geographic distribution, evolution, and disease importance of species within the Neotropical Anopheles albitarsis Group (Diptera, Culicidae). J Vect Ecol. 2014;39(1):168-81.

112. Obsomer $V$, Defourny $P$, Coosemans M. Predicted distribution of major malaria vectors belonging to the Anopheles dirus complex in Asia: ecological niche and environmental influences. PLoS One. 2012;7(11):e50475.

\section{Submit your next manuscript to BioMed Central and take full advantage of:}

- Convenient online submission

- Thorough peer review

- No space constraints or color figure charges

- Immediate publication on acceptance

- Inclusion in PubMed, CAS, Scopus and Google Scholar

- Research which is freely available for redistribution 